\title{
Thyroid Crisis and Hyperosmolar Hyperglycemic State in a Hyperthyroid Patient
}

\author{
Yudith Annisa Ayu Rezkitha ${ }^{1,2,3}$, Rio Wironegoro ${ }^{1}$, Hermawan Susanto ${ }^{1}$, Soebagijo Adi $^{1}$ and Ari \\ Sutjahjo ${ }^{1}$ \\ ${ }^{I}$ Department of Internal Medicine, Universitas Airlangga, Dr. Soetomo General Hospital, Jl. Prof dr. Moestopo Surabaya, \\ Indonesia \\ ${ }^{2}$ Institude of Tropical Disease, Universitas Airlangga, Surabaya, Indonesia \\ ${ }^{3}$ Faculty of Medicine, Universitas Muhammadiyah Surabaya, Surabaya, Indonesia \\ apji@fk.unair.ac.id
}

Keywords: Hyperosmolar Hyperglycemic State, Hyperthyroid, Insulin, Thyroid Crisis.

\begin{abstract}
Hyperthyroidism is one form of thyrotoxicosis caused by excess synthesis and thyroid hormone secretion by the thyroid gland. Thyroid crisis is a life-threatening hyperthyroid exacerbation, characterized by decompensation of one or more organ systems and hyperosmolar hyperglycemic state (HHS) characterized by hyperglycemia, hyperosmolality, and dehydration without ketoacidosis. Cases of thyroid and HHS crises are rarely found in hyperthyroid patients. The purpose of this case report is to describe symptoms for diagnosis, therapy, and prognosis of hyperthyroid patients with thyroid and HHS crises. We reviewed the literature and describe hyperthyroid manifestations with thyroid crisis and HHS. A 30-year-old woman found an increase in pulse rate, body temperature, respiration rate, enlarged diffuse solid $(50 \mathrm{~cm} 3)$, mobile, dry skin, $600 \mathrm{cc} / 4$-hour urine production, Burch-Wartofsky score of 95, elevated blood glucose, and osmolarity blood. Therapies were given under the formula TS 416688-24-6 for thyroid crisis, rehydration, and management of blood sugar levels was used for HHS. The patient showed improvement after five days of care with a good prognosis. It was concluded that thyroid crisis and HHS have a poor prognosis because of the high mortality rates. Identification and the correct diagnosis could improve the prognosis of the case.
\end{abstract}

\section{INTRODUCTION}

Hyperthyroidism is one form of thyrotoxicosis that is caused by excess synthesis and thyroid hormone secretion by the thyroid gland. Meanwhile, thyrotoxicosis itself is a clinical condition resulting from abnormal levels and activities of the thyroid hormone in the tissues. In the United States, the prevalence of hyperthyroidism is about $1.2 \%$ both in the form of hyperthyroid overt $(0.5 \%)$ and subclinical hyperthyroidism $(0.7 \%)$ (Bahn et al. 2011).

Thyroid crisis is a life-threatening exacerbation of hyperthyroidism, characterized by decompensation of one or more organ systems. It is usually a complication of Graves' disease, although occasionally occurs in toxic nodular goiter. Prevalence of thyroid crisis ranges from $<1-2 \%$ of hospitalized thyrotoxicosis patients with high mortality rates, ranging from 20 to $30 \%$. There is no limit of thyroid hormone levels in the circulation to definitively define thyroid crisis. Rapid diagnosis with early drug intervention is essential to reduce morbidity and mortality due to thyroid crisis (Migneco et al., 2005; Carroll and Matfin, 2010).

Hyperosmolar hyperglycemic state (HHS) is characterized by hyperglycemia, hyperosmolality, and dehydration without significant ketoacidosis. This metabolic disorder is the result of an absolute combination or relative deficiency of insulin accompanied by increased hormone counter insulin (glucagon, catecholamine, cortisol and growth hormone). The pathogenesis of HHS is not as clear as DKA. The condition that initiates HHS is glucosuric diuresis. HHS mortality rates range from 10 to $50 \%$, higher than diabetic ketoacidosis with a mortality of 1.2 to $9 \%$. However, actual mortality data are difficult to ascertain because of the high incidence of other accompanying diseases. Age, dehydration rate, hemodynamic instability, underlying triggers, and degree of consciousness are 
strong predictors of fatal complications (Stoner, 2005; Gouveia and Chowdhury, 2013).

Until now there has been no clear correlation between thyroid crisis and HHS incidence. However, the hyperthyroid condition itself could affect the homeostasis of glucose and insulin metabolism. Hyperthyroidism has known to support the occurrence of hyperglycemia. Excess thyroid hormone leads to increased intestinal glucose absorption and an increased gastric emptying rate. Elevated blood sugar levels occur rapidly after oral glucose loading; therefore the blood glucose concentrations might increase rapidly and earlier in 30-60 minutes (more than $200 \mathrm{mg} / \mathrm{dl}$ ). An earlier peak increase often results in glucosuria (Degroot, 2003; Hage, Zantout, and Azar, 2011).

\section{CASE}

A woman, Mrs. S, aged 30 years old, Javanese, senior high school as her basic education, housewife, domiciled in Surabaya, Indonesia, came to the emergency unit of Dr. Soetomo General Hospital Surabaya with the main complaint of high fever. On the first day, the patient complained of fever for 3 days which continued to increase. The symptoms were no coughs, soreness, body rashes and painful urination. However, along with the fever, the patient seemed to experience a change of consciousness in the form of anxiety, difficulty sleeping until sometimes talking rambunctious. There were no seizures, nausea or vomiting. But, the patient could still eat and drink during the illness.

Since 6 months ago the patient had begun to complain that she often felt her heart pounding, both hands trembled, sweated easily, had difficulty sleeping, was often anxious, easily tired, was unable to withstand hot air, and had diarrhea within the last six months. However, complaints about being thirsty and frequent urination were not reported by the patient. There was no history of diabetes, high blood pressure, jaundice, or mumps. There was no consumption of drugs for mumps, high blood pressure, or heart problems. Five days beforehand the patient went for psychiatric treatment and was given a sedative but she did not know its name.

Physical examination results were GCS 345, delirium, blood pressure $120 / 80 \mathrm{mmHg}$, pulse 140 times per minute, respiration rate 28 times every minute without Kussmaul, and a temperature of $39^{\circ} \mathrm{C}$. There was an enlarged diffuse solid of $10 \times 5$ $\mathrm{x} 1 \mathrm{~cm}$, mobile, no pain, no bruising, and no enlarged lymph nodes. On examination of the heart and lung no abnormalities were found. An abdominal examination found normal bowel sounds, suppleness, with no enlargement of the liver and lien. On examination of the limbs there was a warm perfusion, dry skin and no edema. Urine production was $600 \mathrm{cc} / 4$ hours in the emergency room.

Results of laboratory tests: Hemoglobin $(\mathrm{Hb})$ $15.6 \mathrm{~g} / \mathrm{dl}$, hematocrit (Hct) $45.1 \%$ leucocytes $17,100 / \mathrm{uL}$, granulocytes $75 \%$, platelets $140,000 / \mathrm{uL}$, Alanine transaminase (ALT) 170/uL, Aspartate transaminase (AST) 83/uL, albumin $3.86 \mathrm{gr} / \mathrm{dl}$, total bilirubin $3.17 \mathrm{mg} /$ bilirubin dir. $2.2 \mathrm{mg} / \mathrm{dl}$, Blood urea nitrogen (BUN) $123.7 \mathrm{mg} / \mathrm{dl}$, creatinine serum $1.17 \mathrm{mg} / \mathrm{dl}$, random blood glucose (RBG) 450 $\mathrm{mg} / \mathrm{dl}$, C-reactive protein $7.27 \mathrm{mg} / \mathrm{L}$, sodium 160 $\mathrm{mEq} / \mathrm{L}$, potassium: $4.7 \mathrm{mEq} / \mathrm{L}$, chloride $122 \mathrm{mEq} / \mathrm{L}$, $\mathrm{pH}$ 7.42, $\mathrm{pCO}_{2} 28.6 \mathrm{mmHg}, \mathrm{pO}_{2} 94.4 \mathrm{mmhg}, \mathrm{HCO}_{3}-$ $18.7 \mathrm{mmol} / \mathrm{L}, \mathrm{BE}-5.8 \mathrm{mmol} / \mathrm{L}, \mathrm{SO}_{2} 97 \%$, blood ketone $0.3 \mathrm{mmol} / \mathrm{L}, \mathrm{HbsAg}$ negative, HIV rapid non reactive. Urinalysis: glu negative, one positive bilirubin, negative ketone, $\mathrm{pH} 5.5$, negative protein, urobilin 3.2, negative nitrite, erytrosit 0-2, leucocytes, and 0-2 slight epithelium. Radiological examination gave a plain picture of the heart and lung chest within normal limits. ECG examination found Irus sinus tachycardia 160x/minute normal axis.

The above data were used to calculate the score for thyroid crisis using the Burch-Wartofsky score (BW score) and the score of 95 was obtained. In addition to calculation of osmolarity with the formula $2(\mathrm{Na})+$ glucose/18, a value of 345 $\mathrm{mOsm} / \mathrm{kg}$ was obtained.

It concluded that this case was one of Thyroid Crisis and HHS. Therapy given was infusion of 2 Liters of $\mathrm{NaCl} 0.9 \%$ in the first 2 hours, followed by 80 drops every minute for 4 hours, then 30 drops every minute for 18 hours, followed by 20 drops every minute for 24 hours, rapid-acting insulin 4 unit every hour repeated intravenously 3 times with 40 $\mathrm{mg}$ of Thyrozol orally, followed by $10 \mathrm{mg}$ of Thyrozol every 4 hours, one hour after first Thyrozol administration of 6 drops of lugol every 6 hours, 10 $\mathrm{mg}$ pf Propranolol orally every 6 hours and $25 \mathrm{mg}$ of Methyl prednisolone intravenously every 8 hours with a 4-unit backup rapid-acting insulin. Planning of diagnosis complete blood count (CBC), RBG, BUN, CS, SE, ALT, AST, direct and total Bilirubin, FT4, TSH.

On the second day, the patient's awareness improved, the fever disappeared, and there was no diarrhea. Physical examination showed blood pressure 120/90 $\mathrm{mmHg}$, pulse 100 times a minute, respiration rate 28 times every minute, without 
kussmaul, temperature $37^{\circ} \mathrm{C}$ with urine production of 3,000 cc/24 hours. Then, laboratory tests found $\mathrm{Hb} 11.1 \mathrm{~g} / \mathrm{dl}$, Hct $32.5 \%$ leukocyte $5.740 / \mathrm{uL}$, granulocytes $75 \%$, platelets $167.000 / \mathrm{uL}$, ALT 63/uL, AST 48/uL, albumin $3.7 \mathrm{gr} / \mathrm{dl}$, total bilirubin 0.8 $\mathrm{mg} / \mathrm{dl}$, direct bilirubin $0.5 \mathrm{mg} / \mathrm{dl}$, BUN $18 \mathrm{mg} / \mathrm{dl}$, CS $0.4 \mathrm{mg} / \mathrm{dl}$, RBG $224 \mathrm{mg} / \mathrm{dl}, \mathrm{mg} / \mathrm{L}$, sodium 142 $\mathrm{mEq} / \mathrm{L}$, potassium: $3.6 \mathrm{mEq} / \mathrm{L}$, chloride $112 \mathrm{mEq} / \mathrm{L}$, FT4 $3.82 \mathrm{ng} / \mathrm{dL}(0.89-1.76)$, TSH $<0.004 \mathrm{uIU} / \mathrm{mL}$ (0.35-5.50). Therapy: Diet B1 2,100 Kcal/day, infusion of 20 drops of $\mathrm{NaCl} 0.9 \%$ every minute, 10 mg of Thyrozol every 4 hours, 6 drops of lugol every 6 hours, $10 \mathrm{mg}$ of propranolol every 6 hours, $25 \mathrm{mg}$ of methylprednisolone per 8 hours intravenously, rapid-acting insulin 4 u t.i.d. subcutaneously ac.

On day four, the patient's awareness improved, with no fever, no diarrhea, and sleep was already more sound. Physical examination found blood pressure $120 / 90 \mathrm{mmHg}$, pulse 80 times per minute, respiration 28 times every minute, without Kussmaul, temperature $37^{\circ} \mathrm{C}$. Laboratory tests found RBG $117 \mathrm{mg} / \mathrm{dl}$. Therapy given was 2,100 cal/day diet, infusion of 20 drops of $\mathrm{NaCl} 0.9 \%$ per minute, $10 \mathrm{mg}$ of Thyrozol t.i.d. orally, $10 \mathrm{mg}$ of propranolol t.i.d. orally, rapid-acting $4 \mathrm{u}$ t.i.d. subcutaneous ac, with urine production of $2,500 \mathrm{cc} / 24 \mathrm{~h}$.

On the fifth day, the patient had no complaints, and there was no fever. Physical examination showed blood pressure of $120 / 90 \mathrm{mmHg}$, pulse 80 times per minute, respiration rate 20 times per minute, temperature $37^{\circ} \mathrm{C}$ with urine production of $2500 \mathrm{cc} / 24$ hours. Hb $11.5 \mathrm{~g} / \mathrm{dl}$, Hct $30.4 \%$ leukocytes $16,400 / \mathrm{uL}$, granulocytes $46.9 \%$, platelets 195,000/uL, ALT 64/uL, AST 56/uL, sodium 137 $\mathrm{mEq} / \mathrm{L}$, potassium: $3.3 \mathrm{mEq} / \mathrm{L}$, chloride $109 \mathrm{mEq} / \mathrm{L}$, FT4 $2.58 \mathrm{ng} / \mathrm{dL}, \mathrm{TSH}<0.004 \mathrm{uIU} / \mathrm{mL}$ therapy: Diet B1 2,100 Kcal/day, infusion of 20 drops of $\mathrm{NaCl}$ $0.9 \%$ every minute, $10 \mathrm{mg}$ of Thyrozol t.i.d. orally, $10 \mathrm{mg}$ of propranolol t.i.d. oral, rapid-acting $4 \mathrm{u}$ t.i.d. subcutaneous ac.

On the seventh day, the patient did not say she was a little weak, and there was no fever. Physical examination showed blood pressure of 120/90 $\mathrm{mmHg}$, pulse 80 times per minute, respiration rate 20 times every minute, temperature $37^{\circ} \mathrm{C}$ with urine production of $2,000 \mathrm{cc} / 24$ hours. Then, the laboratory tests: $\mathrm{Hb} 10.9 \mathrm{~g} / \mathrm{dl}$, Hct $33 \%$ leukocytes 12,400/uL, granulocytes 47.9\%, platelets 230,000/uL, ALT 24/uL, AST 30/uL, albumin 3.3 $\mathrm{gr} / \mathrm{dl}$. The therapies were diet B1 2,100 Kcal/day, infusion of 20 drops of $\mathrm{NaCl} 0.9 \%$ every minute, 10 $\mathrm{mg}$ of Thyrozol t.i.d. orally, and $10 \mathrm{mg}$ of propranolol t.i.d. orally, and insulin was stopped.
On the eighth day, the patient did not have any complaints. A blood glucose profile examination was performed without using insulin and gave results of GDP/GD2JPP 83/153 and HbA1C 6.7\%. On the ninth day, the patient was discharged with 10 $\mathrm{mg}$ of propranolol t.i.d. and $10 \mathrm{mg}$ of thyrozol t.i.d. orally.

\section{DISCUSSION}

In hyperthyroid patients, FT4 thyroid levels increase with undetectable TSH indicating an overt hyperthyroidism. Symptoms of hyperthyroidism include thyroid gland enlargement with tachycardia, palpitations, tremor, not heat resistant, anxiety, hyperkinesia, fatigue, diarrhea, exophthalmos, muscle weakness and paralysis. Older patients exhibit more prominent cardiovascular symptoms such as dyspnea and atrial fibrillation, as well as unexplained weight loss. Patients at a younger age tend to exhibit symptoms of sympathetic activity such as anxiety, hyperactivity, and tremor. In overt hyperthyroidism, free $\mathrm{T} 4$, and $\mathrm{T} 3$ levels increase, and TSH is not detected, whereas in mild hyperthyroidism, free serum $\mathrm{T} 4$ and $\mathrm{T} 4$ may be normal, and only T3 alone increases with undetectable TSH. Subclinical hyperthyroidism has normal free T4, T3 and free T3 with subnormal serum TSH (Migneco et al., 2005; Nayak and Burman, 2006; Karnath, 2006).

The patient had pounding $(+2)$, easily get tired $(+2)$, cannot withstand hot air $(+5)$, often feel anxious $(+2)$, palpable diffuse struma $(+3)$, tremor $(+4)$ warm extremities $(+2)$ and $140 \mathrm{x} / \mathrm{m}(+3)$ pulse with a total score of Wayne index of 23 . Therefore, the patient was diagnosed with hyperthyroidism. Hyperthyroid status can be determined by calculating the Wayne Index. A total score < 10 indicates a condition of euthyroid, if the score is 1020 then there is a possibility of a hyperthyroid and if $>20$ then definitely a hyperthyroid (Carroll and Matfin, 2010).

Patients with anamnesis have the possibility of triggering factors in the form of consumption of sedatives previously obtained from psychiatric doctors. Thyroid crisis usually occurs in hyperthyroid patients previously exposed to certain trigger factors, such as infection, thyroid gland surgery, sudden antithyroid cessation, childbirth, severe stress, excessive thyroid palpation, pseudoephedrine, amiodarone, toxemia gravidarum and tooth extraction which have also been reported for tranquillizers, lithium, iodine-based contrast, 
chemotherapy, aspirin and intoxication of organophosphates (Klubo-Gwiezdzinska and Wartofsky, 2012).

The patient did not meet the classical diagnosis criteria of GOP-39, 5-120 then calculated as nonclassical. Based on a temperature of $39^{\circ} \mathrm{C}(20)$, with delirium (20), hyperbilirubinemia (20), pulse 140 $\mathrm{x} / \mathrm{min}(25)$, and a suspected trigger factor of sedation (10), the total BW score was 95 so the patient was diagnosed with thyroid crisis. Classical Thyroid Storm can be diagnosed in the presence of goiter $(\mathrm{G})$ and/or orbita; (O) signs and precipitant (P) plus body temperature $>39.5^{\circ} \mathrm{C}$ and heart rate or tachycardia $>120 / \mathrm{min}$. All of these components can be termed as: Formula G/O-P-39.5-120. This formula may result in a total score $>50$ which can be calculated in detail as follows: $\mathrm{P}$ (precipitant) with score 10 , temperature of $39.5^{\circ} \mathrm{C}$ with a score of 25 and tachycardia with a score of 15 . If the examination results do not meet the classical diagnostic criteria then non-classical criteria using Burch-Wartofsky (BW score) should be used. A score of $<25$ means that the patient was not in a thyroid crisis state as a score of 25-44 means the patient is in a state of impending thyroid crisis. When $\geq 45$, it means the patient is in a thyroid crisis situation (Tjokroprawiro, 2015).

Patients are seen to experience an awareness change in the form of anxiety, difficulty sleeping until sometimes talking rambunctious. Physical examination gave GCS 345, delirium with a pulse of $140 \mathrm{x} / \mathrm{m}$. Patients with HHS usually exhibit symptoms of weakness, visual disturbance or leg cramps, sometimes with nausea and vomiting, but less frequently than patients with diabetic ketoacidosis. Clinical symptoms can include severe dehydration from the decrease of tissue turgor, dry cheek mucosa, sunken eyes, cold extremities and rapid pulse. It could be accompanied by subfebris or not. More severe symptoms may include neurological symptoms such as lethargy, confusion, hemiparesis (not infrequently diagnosed as cerebrovascular accident), seizures or coma (Stoner, 2005; Carroll and Matfin, 2010).

In this patient we found an increased of random

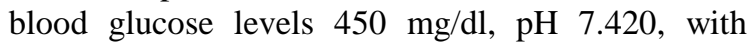
normal blood ketone $0.3 \mathrm{mmol} / \mathrm{L}$, blood osmolarity increased $345 \mathrm{mOsm}$, hemoglobin, hematocrit $\mathrm{Hb}$ $15.6 \mathrm{~g} / \mathrm{dl}$, Hct 45.1\%, BUN $123.7 \mathrm{mg} / \mathrm{dl}$, and sodium content $160 \mathrm{mEq} / \mathrm{L}$. The typical findings of laboratory patients with HHS include elevated blood glucose levels and serum osmolarity above 320 $\mathrm{mOsm} / \mathrm{kg}$ of water with a $\mathrm{pH}$ above 7.30 without ketonemia. Sodium levels could be increased or normal, while creatinine, blood urea nitrogen (BUN) and hematocrit levels almost always increase (Kitabchi et al., 2009; Gouveia and Chowdhury, 2013).

Thyroid hormone affects glucose metabolism through several mechanisms. In hyperthyroid conditions there is increased intestinal glucose absorption and increased endogenous glucose production, especially from gluconeogenesis and glycogenolysis derived from lipolysis stimulated by increased catecholamines due to excess thyroid hormone, increased Cori cycle activity, a cycle of lactic acid delivery to the liver to be converted into glucose and sent back to the muscles, and increased plasma amino acid concentrations such as glutamine and alanine (Dimitriadis and Raptis, 2001; Hage, Zantout, and Azar, 2011).

Increased excessive glucose absorption of the gut that is accompanied by increased glycogenolysis and gluconeogenesis leads to an increase in insulin requirement. In hyperthyroid patients, it tends to require very high insulin before hyperthyroidism is controlled. An increase in fasting insulin production was twice the normal value and increased insulin production after eating that could be seen from $C$ peptide markers produced by $\beta$-pancreatic cells. However, despite the increase in insulin production, there is also decreased in insulin quality and insulin sensitivity at the periphery, as well as the decreased of insulin ability to suppress the production of glucose from the liver (Makuno, 1999; Degroot, 2003). Several studies have also shown that with a hyperthyroid there is an increase in plasma insulin degradation so that the speed of insulin client also increases (Potenza, Via, and Yanagisawa, 2009; Lambadiari et al., 2011).

Patients with previous hyperthyroid complaints for six months allow for homeostasis of glucose and insulin, and in the presence of a crisis thyroid, it triggers a sudden increase in glucose conditions leading to glucosuria and the start of HHS events. The pathogenesis of HHS is not as clear as DKA. The condition that initiates HHS is called glucosuric diuresis. Under normal conditions, the kidneys will act as a safety valve to eliminate glucose over certain threshold values and prevent further accumulation of blood glucose. However, decreased intravascular volume or decreased glomerular filtration rate (GFR) due to kidney disease will lead to increased glucose levels. Losing more water than sodium will cause hyperosmolarity. Insulin persists, even in large amounts, enough to prevent excessive lipolysis and ketoacidosis, but not adequately 
enough to lower glucose levels (Kitabchi et al., 2009).

In patients with hyperbilirubinemia, total bilirubin increase is $3.17 \mathrm{mg} / \mathrm{dl}$, and bilirubin direk is $2.2 \mathrm{mg} / \mathrm{dl}$, birubinuria +1 , and increased transaminase SGOT $170 / \mathrm{uL}$ and SGPT 83/uL. Bilirubin levels improved on the second day of care and transaminase improved on the fifth day of treatment without the need for special treatment.

Hepatic dysfunction due to thyrotoxicosis is relatively frequent and classified into hepatitis or cholestatic type. In the hepatitic type there is an increase in SGOT (AST) and SGPT (ALT), respectively in $27 \%$ and $37 \%$ of patients. Most of these patients exhibit no other signs of impaired hepatic function either clinically or in the laboratory. The mechanism of hepatic dysfunction is allegedly due to relative hypoxia in the perivenuler due to increased oxygen demand of hepatic tissue not followed by increased blood flow to the liver. Clinical features of this type resemble self-limiting hepatitis although some patients were reported to have fulminant liver failure. In the cholestatic type, serum alkaline phosphatase, $\gamma$-glumatyl transpeptidase and bilirubin increased. Icterus is generally not too heavy, but if found the possibility of thyroto should be ruled out (Khemichian and Fong, 2011).

The patients was given $40 \mathrm{mg}$ of Thyrozol orally, followed by $10 \mathrm{mg}$ of thyrozol every 4 hours; one hour after the first Thyrozol administration, 6 drops of Lugol was given every 6 hours, with $10 \mathrm{mg}$ of Propranolol orally every 6 hours and $25 \mathrm{mg}$ of Methylprednisolone intravenously every 8 hours. Clinical improvement appeared within one day of treatment and the thyroid crisis improved on the fifth day of treatment.

There was no difference in hyperthyroid therapy that triggers both HHS and hyperthyroidism and stand-alone HHS. Therapy for thyroid crisis is divided into two parts: supportive therapy which includes fluid administration to overcome dehydration, oxygen delivery, NG tube installation if necessary, cold compress and acetaminophen to reduce heat, maintain electrolyte balance and sedative administration if necessary, and special therapy with formula TS 416688-24-6, which is a formula used in Dr. Soetomo General Hospital. The drugs used were as follows: (4) Initial dosing of 400 $\mathrm{mg}$ of PTU followed by maintenance doses of 100 mg every 4 hours. It could also be Methimazole with an initial dose of $40 \mathrm{mg}$ of PO and a maintenance dose of 10 mg every 4 hours. (1) PTU administration at least one hour after lugol therapy. (6) The giving of lugol droplets was every 6 hours. Lugol was given as much as 6 drops or $0.25 \mathrm{~g}$ of sodium iodide intravenously. (6) Provision of $10-40 \quad \mathrm{mg}$ propranolol tablets was every 6 hours (8) Administration of $100 \mathrm{mg}$ of hydrocortisone or $2 \mathrm{mg}$ of dexamethasone or $25 \mathrm{mg}$ of methylprednisolone was done intravenously every 8 hours. Clinical improvement should be achieved within 24 hours and thyroid crisis should improve within 6 days (Tjokroprawiro 2015).

In patients given an infusion of 2 Liters of $\mathrm{NaCl}$ $0.9 \%$ in the first 2 hours, 80 drops are given every minute for 4 hours, 30 drops every minute for 18 hours, followed by 20 drops per minute in every 24 hours, rapid-acting insulin $4 \mathrm{U}$ every hour which is repeated intravenously 3 times.

The management of HHS in Dr. Soetomo General Hospital is performed in two phases. The first phase includes rehydration using $\mathrm{NaCl} 0.9 \%$ or 2 liters of RL in 2 hours, followed by 80 drops every minute for 4 hours, followed by 30 drops every minute for 18 hours, then 20 drops every minute in 24 hours. Then, the control of blood sugar is achieved with minus one formula of rapid-acting insulin intravenously. Potassium infusion was Given when we found hypokalemia. Antibiotics is given with adequate rational judgement and dose rulings. The second phase begins when the blood glucose has reached $<250 \mathrm{mg} / \mathrm{dl}$ or there is negative urine reduction, including administration of $0.9 \% \mathrm{NaCl}$ or parenteral peripheral nutrition if necessary, with control of blood sugar with subcutaneous rapidacting insulin with a dose of formula (Tjokroprawiro, 2015).

These patients have a good prognosis both because of adequate therapy, and having a young age, with moderate dehydration, stable hemodynamics, and a lack of consciousness that is not serious. Thyroid crisis has a poor prognosis due to high mortality rates if not detected properly or not managed properly, with the main cause of death being the originator and disease (Akamizu, 2012; Akamizu et al., 2012). While HHS itself has a higher mortality rate in older people, severe dehydration, unstable hemodynamics, unclear trigger, and severe degree of awareness, compared to DKA (Kitabchi et al., 2009).

\section{CONCLUSION}

A 30-year-old woman with a diagnosis of thyroid crisis and HHS has been reported. Diagnosis of thyroid crisis was established using the Burch- 
Wartofsky score (BW score), and the score was 95. Meanwhile, the HHS diagnosis was based on elevated blood glucose and blood osmolarity. The patient was given therapy to overcome the thyroid crisis based on TS 416688-24-6 formula along with HHS therapy in the form of rehydration and management of blood sugar levels. The patient showed improvement after five days of treatment and the prognosis was good.

\section{REFERENCES}

Akamizu, T. 2012. '[Diagnosis and treatment of thyroid storm]', Nihon Rinsho, 70: 2000-4.

Akamizu, T., T. Satoh, O. Isozaki, A. Suzuki, S. Wakino, T. Iburi, K. Tsuboi, T. Monden, T. Kouki, H. Otani, S. Teramukai, R. Uehara, Y. Nakamura, M. Nagai, M. Mori, and Association Japan Thyroid. 2012. 'Diagnostic criteria, clinical features, and incidence of thyroid storm based on nationwide surveys', Thyroid, 22: 661-79.

Bahn, R. S., H. B. Burch, D. S. Cooper, J. R. Garber, M. C. Greenlee, I. Klein, P. Laurberg, I. R. McDougall, V. M. Montori, S. A. Rivkees, D. S. Ross, J. A. Sosa, M. N. Stan, Association American Thyroid, and Endocrinologists American Association of Clinical. 2011. 'Hyperthyroidism and other causes of thyrotoxicosis: management guidelines of the American Thyroid Association and American Association of Clinical Endocrinologists', Endocr Pract, 17: 456-520.

Carroll, R., and G. Matfin. 2010. 'Endocrine and metabolic emergencies: thyroid storm', Ther Adv Endocrinol Metab, 1: 139-45.

Degroot, L.J. 2003. 'Graves Disease and the manifestation of thyrotoxicosis', The thyroid and its disease.

Dimitriadis, G. D., and S. A. Raptis. 2001. 'Thyroid hormone excess and glucose intolerance', Exp Clin Endocrinol Diabetes, 109 Suppl 2: S225-39.

Gouveia, C. F., and T. A. Chowdhury. 2013. 'Managing hyperglycaemic emergencies: an illustrative case and review of recent British guidelines', Clin Med (Lond), 13: $160-2$.

Hage, M., M. S. Zantout, and S. T. Azar. 2011. 'Thyroid disorders and diabetes mellitus', J Thyroid Res, 2011: 439463.

Karnath, B., Hussain, N.,. 2006. 'Sign and Symptom of Thyroid disfunction', Hospital Physician: 43-48.

Khemichian, S., and T. L. Fong. 2011. 'Hepatic dysfunction in hyperthyroidism', Gastroenterol Hepatol (N Y), 7: 337-9.

Kitabchi, A. E., G. E. Umpierrez, J. M. Miles, and J. N. Fisher. 2009. 'Hyperglycemic crises in adult patients with diabetes', Diabetes Care, 32: 1335-43.

Klubo-Gwiezdzinska, J., and L. Wartofsky. 2012. 'Thyroid emergencies', Med Clin North Am, 96: 385-403.
Lambadiari, V., P. Mitrou, E. Maratou, A. E. Raptis, N. Tountas, S. A. Raptis, and G. Dimitriadis. 2011. 'Thyroid hormones are positively associated with insulin resistance early in the development of type 2 diabetes', Endocrine, 39: 28-32.

Makuno, T. 1999. 'Glucose transport concentration in hyper and hypothyroid rat', J Endocrinol Invest, 160: 285.

Migneco, A., V. Ojetti, A. Testa, A. De Lorenzo, and N. Gentiloni Silveri. 2005. 'Management of thyrotoxic crisis', Eur Rev Med Pharmacol Sci, 9: 69-74.

Nayak, B., and K. Burman. 2006. 'Thyrotoxicosis and thyroid storm', Endocrinol Metab Clin North Am, 35: 663-86, vii.

Potenza, M., M. A. Via, and R. T. Yanagisawa. 2009. 'Excess thyroid hormone and carbohydrate metabolism', Endocr Pract, 15: 254-62.

Stoner, G. D. 2005. 'Hyperosmolar hyperglycemic state', Am Fam Physician, 71: 1723-30.

Tjokroprawiro, A., Novida, H.,. 2015. Krisis tiroid (Airlangga University Press: Surabaya). 